\title{
Does the Law of One Price Hold for South African Exchange Traded Funds?
}

\author{
Ailie Charteris \\ School of Accounting, Economics and Finance, University of KwaZulu-Natal, South Africa \\ Email: charterisa@ukzn.ac.za
}

\section{Doi:10.5901/mjss.2014.v5n3p183}

\begin{abstract}
Exchange-traded funds (ETFs) trade at a market-determined price, which should be equal to their Net Asset Value (NAV) based on the law of one price. This study examines whether a long-run equilibrium relationship between the price and NAV exists for four South African-listed ETFs using Johansen's cointegration. A common stochastic trend is found between the price and NAV for all the funds; however, this relationship only conforms to the law of one price for three of the four funds. Both the price and NAV are found to correct for the disequilibrium in the long-run relationship which is surprising as if the arbitrage process of creating and deleting units associated with ETFs was the predominant driver of the equilibrium relationship as theory suggests, then it would be expected that only the price would adjust to correct for any disequilibrium. The profile persistence analysis confirms that the deviations from the NAV do not persist. The findings of this study thus suggest that the market for ETFs in South Africa is reasonably efficient and hence retail investors are not likely to be exposed to substantial mispricing which could adversely affect their returns from holding ETFs.
\end{abstract}

Keywords: exchange traded funds, pricing deviation, cointegration, efficiency.

\section{Introduction}

ETFs are considered to be one of the most innovative financial products introduced in the past twenty years and accordingly have attracted considerable retail and institutional participation. An ETF is an index fund that aims to replicate the performance of a particular benchmark index as closely as possible, much like open-end funds; but they have the characteristic of closed-end funds in that they are listed on an exchange, and shares in the fund can be bought and sold intraday at the market price (Deville, 2008). Thus, short-selling, stop-loss orders, limit orders and margin trading are all allowed with ETFs. This renders trading equity-baskets easier and promotes risk-diversification. Moreover, ETFs offer greater tax advantages, liquidity, transparency, lower management fees and more efficient dividend treatment than associated with open-end funds (Gastineau, 2002; Kostovetsky, 2003; Gastineau, 2004).

Buying and selling ETF shares is not only limited to the secondary market, but units can be created and deleted by purchasing or selling the constituent shares with the ETF custodian company. This can only be done by the authorised participants, either institutional investors or market makers (Deville, 2008). ETFs thus have two prices: their market determined value and the NAV. The law of one price states that securities should have the same price in different markets provided that they are linked by arbitrage (Hasbrouck, 1995); therefore, the NAV and price of the ETF share should be equal. But, given that markets are not perfect, information is not disseminated instantaneously, and because the NAV is only computed at the end of the day, it is possible that the market price and NAV of the fund may differ. However, in contrast to closed-end funds these two prices should not deviate too far from each other, because investors can create and delete units to profit from any mispricing, thus driving the market price back towards equilibrium.

Several studies have analysed the extent to which the price and NAV of ETFs are equal. Initial studies examined the magnitude and variation in the price deviation (the difference between price and NAV) over time in dollar and percentage terms. In addition, they typically analysed how quickly the deviations disappear over time, arguing that if they do not persist then the ETFs can be considered price efficient. However, these studies do not actually test the law of one price directly, as the theory implies the existence of a long-run relationship between the price and NAV, which is not examined. That is, if price and NAV are found to exhibit a long-run equilibrium relationship, then the deviations examined can be viewed as short-run deviations from the long-run relationship and, accordingly, will only be temporary in nature. In contrast, if no such long-run equilibrium relationship exists, then it implies that the two series wander apart from each other as there is no stochastic trend linking the two together as theory implies. Accordingly, more recent studies of the price deviations have focused on examining whether a long-run relationship exists between price and NAV using 
cointegration methodology.

The Johannesburg Securities Exchange (JSE) is one of the most advanced emerging markets in the world given its strong institutional frameworks, and thus has provided a solid foundation for the development of an ETF market. Since its inception in 2000, the market for ETFs has grown rapidly, as institutions seek to provide more product offerings and investors are taking up positions in these index funds. However, despite the size of the ETF market in South Africa, very little research has been conducted on these instruments. The one exception to this is the recent study of Charteris (2013), who examined the characteristics of the pricing deviations. She found that the deviations of the funds were significant although they appeared to disappear quite quickly; partially attributable to the efficient execution of arbitrage. However, Charteris (2013) does not consider whether these deviations are simply temporary deviations from the long-run relationship or whether a long-run relationship even exists. This study thus seeks to fill this notable gap in the literature by analysing the price efficiency of South African ETFs by considering the extent to which a long-run relationship exists between price and NAV for several domestic ETFs.

The remainder of this paper is set out as follows: in Section 2, relevant studies of price efficiency and the law of one price in ETF markets internationally are reviewed. In Section 3, the methodology employed in this study and the results of the analysis are discussed. Finally, in Section 4, the conclusions and recommendations for future research are documented.

\section{Literature Review}

Efficiency is a crucial concept in finance as it has important implications for the choices investors' make to trade. A variety of approaches have been adopted to examine the efficiency of financial markets and the ETF market is no exception. An ETF trades at a market determined price, which is affected by supply and demand; but at the same time, the ETF also has a NAV, which is a function of the values of its constituent securities. If markets are efficient, then the NAV and price should be identical; that is, if there is any mispricing, arbitrageurs will attempt to profit from this by buying low and selling high and thus driving prices back to their true underlying values.

Initial studies of the efficiency of ETF markets focused on the dollar and percentage deviations of the price of the Spider ETF from its NAV, which tracks the Standard \& Poor's 500 Index. Ackert and Tian (2000) document that there was considerable variation in the price deviations over time, with the Spider trading at a premium of $0.07 \%$ on average after adjusting for dividends. Whilst this premium was statistically significant, it was not found to be economically significant. They also found that the volatility of the ETF was not sufficiently different from that associated with the underlying index, thus confirming that ETF pricing was relatively efficient. Elton et al. (2002), in contrast, documented that the Spider traded at a small discount of $0.018 \%$ on average over the period reviewed. They examined the persistence in the percentage deviations by considering the influence of lagged deviations on the current period deviation and found that the mispricing of the Spider disappeared within one day. The magnitude of the price deviation had a significant positive relationship with trading volume, which thus signals that the adept execution of arbitrage contributed to market efficiency.

Jares and Lavin (2004) found that foreign ETFs generally trade at much higher (or lower) premiums (or discounts) relative to their NAV than domestic funds, as evinced by the Japanese and Hong-Kong i-Shares listed in the United States (U.S.), which traded at an average discount of $0.34 \%$ and $0.21 \%$ over the period reviewed. The deviations were found to have substantial forecasting power for following day returns such that a discount today would signal a positive return the following day. Accordingly, Jares and Lavin (2004) developed a simple trading strategy based on the end of day price deviation of the ETFs and found that it outperformed a buy-and-hold strategy. Cherry (2004) devised a similar trading strategy for three foreign ETFs and confirmed that this strategy earned excess returns of 15\% per annum net of transaction costs, whilst simultaneously exposing the investor to less risk. In addition to this, Cherry (2004) found that ETFs exhibited greater volatility than the underlying index; a result confirmed by Tse and Martinez (2007) in examining only international ETFs listed in the U.S. Taken together these results suggest that the market for foreign ETFs listed on the U.S. market is inefficient, which Cherry (2004) attributes to investor irrationality, and suggests that investors in this market may be preoccupied with forecasting prices based on trends rather than fundamental value.

Engle and Sarkar (2006) also examined domestic and foreign listed ETFs in the U.S. and confirmed that the price deviations for the domestic funds were generally small and disappeared rapidly, whilst for the foreign funds the deviations were considerably larger and persisted for several days. Engle and Sarkar (2006) attribute the less efficient pricing of international ETFs to the costs and complexity associated with the creation and redemption of international products. 
Internationally, Gallagher and Segara (2005) have examined the price deviations of Australian ETFs, finding that the price deviations of domestic funds were reasonably small and disappeared within one day. For developing markets, Lin et al. (2005) and Kayali (2007) found that the Taiwanese and Turkish ETFs traded at statistically significant deviations from their NAV, but these deviations disappeared within two days of trading. In South Africa, Charteris (2013) found that six of the seven funds examined traded at a significant premium or discount to their NAV, although most of these deviations were not found to persist for more than two days.

More recently, studies of price efficiency have diverted away from considering persistence in the deviation via an autoregressive framework based on the view that these deviations can only be considered temporary if a long-run equilibrium relationship exists between price and NAV. Accordingly, several authors have used cointegration techniques to ascertain whether the pricing of ETFs is efficient. Fujiwara (2006) compared the efficiency of the Nikkei 300 ETF in Japan to the Spider fund. Using both the Johansen and Engle-Granger cointegration tests, Fujiwara (2006) found that the Spider price and NAV were cointegrated, whereas for the Nikkei 300, there was only evidence of a long-run relationship using Johansen's method. Furthermore, the cointegrating vector of $(1,-1.032)$, although not tested, revealed a large coefficient on the NAV, suggesting that even though a long-run relationship may be present the relationship is not in accordance with the law of one price of $(1,-1)$. In contrast for the Spider, the estimated co-integrating vector based on Johansen's method was $(1,-1.001)$. Thus, there is some evidence to suggest that the Japanese ETF pricing is not efficient as is the case with the Spider fund.

Delcoure and Zhong (2007) examined $20 \mathrm{i}$-Shares that track country indices. They found that there was a common stochastic trend between the price and NAV for every ETF using the Johansen's cointegration approach. They did not test but simply argued that most of the cointegrating vectors were close to unity in accordance with the law of one price. Delcoure and Zhong (2007) implement the persistence profile analysis of Pesaran and Shin (1996), which examines how quickly the price-NAV system reacts to a system-wide shock. The profile should approach zero as the time horizon examined increases, as the shock to the system is temporary and the long-run equilibrium relationship should be restored. Delcoure and Zhong (2007) found that for all the i-Shares (except Malaysia and Australia), 95\% of the convergence to equilibrium occurred within two trading days, with the Australian fund taking four days and the Malaysian fund 20 days. Thus, despite the timing differences between the market on which the i-Shares are traded and the markets on which the underlying shares are listed, these ETFs are reasonably price efficient as the deviations are only temporary and do not persist.

De Fusco et al. (2011) examined the price efficiency of the Spider, Diamond and Cube ETFs on the U.S. market. Similarly to Fujiwara (2006), they found that the Spider fund was price efficient based on the Engle-Granger test of cointegration, as was the Diamond fund. However, there was mixed evidence regarding the Cube ETF, as over the whole period of examination the pricing deviation was found to be non-stationary.

\section{Methodology and Analysis}

\subsection{Data and Descriptive Statistics}

This study focused only on domestic funds; that is, ETFs that track indices comprising South African firms only. The international literature has demonstrated that domestic funds are likely to be more efficient than foreign funds because the latter are affected by timing mismatches between the country of origin and the South African market. The four funds examined are the Satrix 40, FINI, INDI and RESI ETFs. The period from the 30 th June 2008 to the $7^{\text {th }}$ December 2012 was examined. The daily closing prices for each ETF were obtained from McGregor BFA and the NAVs from Profile Media.

The rand price deviation of the funds were computed as shown in equation 1 and the t-statistic used for testing the significance thereof was computed as detailed in equation 2.

$$
\begin{aligned}
& D_{t}=P_{t}-N A V_{t} \\
& T-\text { Statistic }=\bar{D}_{t} /(s / \sqrt[2]{n})
\end{aligned}
$$

where: $P_{t}$ is the closing price, $N A V_{t}$ is the NAV, $D_{t}$ is the daily rand price deviation, $\bar{D}_{t}$ is the mean rand deviation, $s$ is the standard deviation of the series and $n$ is the number of observations in the sample. If $\bar{D}_{t}$ is positive, the fund is said to be trading at a premium to its NAV whilst the opposite is true if $\bar{D}_{t}$ is negative. The summary statistics for the rand price deviations for the four funds are documented in Table 1. The Satrix 40, INDI and FINI funds were all found to trade at a discount on average, whereas the Satrix RESI traded at a premium to its NAV. The t-statistics are significant for all of the funds except for the Satrix RESI signalling that the prices of these ETFS regularly trade away from their true 
underlying value.

Table 1: Summary Statistics for the Rand ETF Price Deviation from NAV

\begin{tabular}{|l|c|c|c|c|c|}
\hline & Average & Standard Deviation & T-statistic & Minimum & Maximum \\
\hline Satrix 40 & -0.01 & 0.10 & $-2.99^{*}$ & -0.87 & 0.66 \\
\hline Satrix FINI & -0.01 & 0.06 & $-2.73^{*}$ & -0.79 & 0.97 \\
\hline Satrix INDI & -0.02 & 0.12 & $-6.72^{*}$ & -0.86 & 1.77 \\
\hline Satrix RESI & 0.01 & 0.57 & 0.70 & -6.32 & 9.16 \\
\hline
\end{tabular}

*Significant at $1 \%$.

\subsection{Cointegration and the Law of One Price}

All variables were found to be non-stationary in levels but stationary in first differences, according to the Augmented Dickey Fuller test (with no trend or intercept). Following Delcoure and Zhong (2007), it was necessary to ascertain whether the deviations documented in Table 1 are temporary by determining whether there is a long-run equilibrium relationship between price and NAV in accordance with the law of one price. Statistically this is captured by the existence of a cointegrating relationship between the two series, and Johansen's technique was used for this purpose. Both the maximum eigenvalue and trace statistics were computed so as to ascertain the number of cointegrating vectors in the system, as follows:

$$
\begin{aligned}
& \text { Trace }=-T \sum_{k=r+1}^{2} \ln \left(1-\hat{\lambda}_{r+1}\right) \\
& \text { Max Eig }=-T \ln \left(1-\hat{\lambda}_{r+1}\right)
\end{aligned}
$$

where: $T$ is the number of observations, $r$ is the hypothesised number of cointegrating relationships and $\hat{\lambda}_{r+1}$ is the $r+1$ order eigenvalue from $T$ (Asteriou and Hall, 2011:374). The tests were conducted with an intercept in the cointegrating vector and the vector autoregression (VAR), as this form of test was determined to be optimal, based on the Schwarz-Bayesian Information Criterion (SBIC). Moreover, for each fund, one lag was included in the VAR, as this was deemed to be the optimal specification, as indicated by the SBIC.

The cointegrating residual in the bivariate framework can thus be written as:

$\xi_{t}=\gamma_{1} P_{t}-\gamma_{2} N A V_{t}$

where: $\gamma_{1}$ is normalized to one and $\gamma_{2}$ is the corresponding cointegrating coefficient and should be equal to 1 if the law of one price holds (Delcoure and Zhong, 2007:175). In this case, $\xi_{t}$, the co-integrating residual, is the rand premium of the fund. In previous studies, authors have only considered whether $\gamma_{2}$ closely approximates 1 ; however, in this study the extent to which the law of one price holds was explicitly tested. This was done by imposing the restriction on the cointegrating vector that $\gamma_{1}=1$ and $\gamma_{2}=-1$, and this was tested using a chi-squared test.

The trace and maximum eigenvalue test statistics for the null hypothesis that there are no cointegrating vectors are displayed in Table 2. The statistics from both tests for all the funds are significant (at 1\%) and this signals that there is a common stochastic trend binding together the NAV and price of the ETFs. Therefore, the deviations between price and NAV can be considered as short-run movements away from a long-run relationship. This mirrors the findings of Delcoure and Zhong (2007) for the 20 i-Shares, and Fujiwara (2006) and De Fusco et al. (2011) for the Spider fund. Similarly to the previous studies, the estimates of $\gamma_{2}$ are close to unity, and this is confirmed statistically for the Satrix 40 and RESI funds, where the law of one price holds perfectly. There is also weak evidence that the relationship holds for the Satrix INDI as the null hypothesis can only be rejected at the 10\% level. However, for the Satrix FINI, the 1:1 relationship between price and NAV does not hold perfectly, similarly to the finding of Fujiwara (2006) for the Nikkei 300 ETF. This indicates that even though the price and NAV have a long-run relationship and do not wander apart from each other, it is not a 1:1 relationship, which means that the discount at which the Satrix FINI trades is likely to persist in the long-run.

Table 2: Cointegration Tests

\begin{tabular}{|l|c|c|c|c|}
\hline & \multicolumn{2}{|c|}{$\mathrm{H}_{0}: \mathrm{r}=\mathbf{0}$} & $\gamma_{\mathbf{2}}$ & Test of the Cointegrating Vector \\
\hline & Trace & $\lambda$ Max & & Chi-Squared Statistic \\
\hline Satrix 40 & $425.0235^{\star}$ & $424.0250^{\star}$ & -0.9999 & 0.008 \\
\hline Satrix FINI & $422.9857^{\star}$ & $422.4690^{\star}$ & -0.9966 & 5.154 \\
\hline Satrix INDI & $446.9969^{\star}$ & $446.0876^{\star}$ & -0.9989 & $3.704^{\#}$ \\
\hline Satrix RESI & $395.2755^{\star}$ & $379.4137^{\star}$ & -0.9990 & 0.087 \\
\hline Critical Values & 15.4947 & 14.2646 & & \\
\hline
\end{tabular}


*Significant at $1 \%,-$ significant at $5 \%$, \# significant at 10\%. The critical values for the trace and maximum-eigenvalue tests are obtained from MacKinnon et al. (1999).

Deviations from this shared trend between price and NAV will occur in the short-run, but it is important to ascertain whether these deviations represent transitory movements in the NAV and/ or the price of the fund. That is, examining the correction term enables the question of which series moves to restore equilibrium to be answered. For this purpose, the error correction term in the VAR, measured as $\xi_{t-1}$, captures the movements of both the price of the fund and the NAV to restore equilibrium. The values of the correction term are shown in Table 3. Overall, the funds largely reflect the same pattern that both the NAV and price adjust to restore equilibrium; although the price does seem to move more as evidenced by the magnitude of the estimate in the price equations compared to the NAV equations. The exception to this is the INDI fund where only the correction term in the price equation is significant. The finding that the price moves to restore equilibrium is expected, as based on the creation and redemption process associated with ETFs if investors seek to profit from any mispricing, this should drive the price of the fund back to equality with the NAV. However, the fact that the NAV also moves is surprising as it would be expected that this value would largely reflect the fundamental value of the component securities. This may tie in with the findings of Charteris (2013) that arbitrage execution in the domestic ETF market in South Africa is not that common. Nevertheless, the findings of this study do confirm that the movement of price is more substantial than the correction by the NAV.

Table 3: Error Correction Terms

\begin{tabular}{|l|l|l|}
\hline \multicolumn{1}{|c|}{$\boldsymbol{\xi}_{\boldsymbol{t}-1}$} & $\mathrm{D}($ Price) & $\mathrm{D}(\mathrm{NAV})$ \\
\hline Satrix 40 & $-0.6027^{\star}$ & $0.3553^{\star}$ \\
\hline Satrix FINI & $-0.5877^{\star}$ & $0.3597^{\star}$ \\
\hline Satrix INDI & $-0.8569^{\star}$ & 0.1104 \\
\hline Satrix RESI & $-0.4298^{\star}$ & $0.4065^{\star}$ \\
\hline
\end{tabular}

*Significant at 1\%," significant at $5 \%$.

It is also of value to determine how quickly equilibrium is restored following a shock to the system for the four funds. For this purpose, the persistence profile analysis of Pesaran and Shin (1996) was used, as this measures the time profile of variable specific shocks on the cointegrating relations of the model. This was performed and the graphs of the results are shown in Figure 1. Equilibrium is restored between the Satrix 40 price and NAV within one day of the shock, although there is a slight deviation again two days after, but it is insignificant. Much the same pattern is evident for the Satrix FINI and INDI funds. Equilibrium is only restored for the Satrix RESI four days after the shock, but the responses are only significant for the first two days. The convergence to equilibrium within two days mirrors the finding of Delcoure and Zhong (2007) for the majority of i-Shares examined, and indicates that there is little opportunity for investors to profit from the short-run deviations from the long-run relationship.

Figure 1: Profile Persistence Analysis

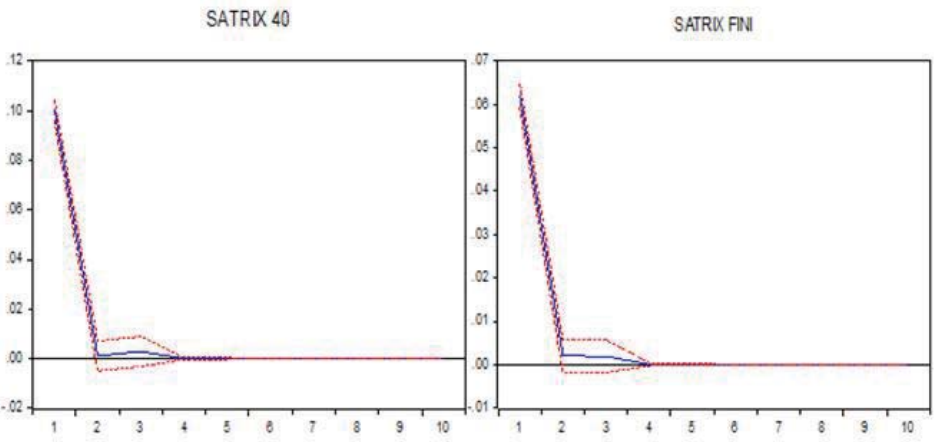



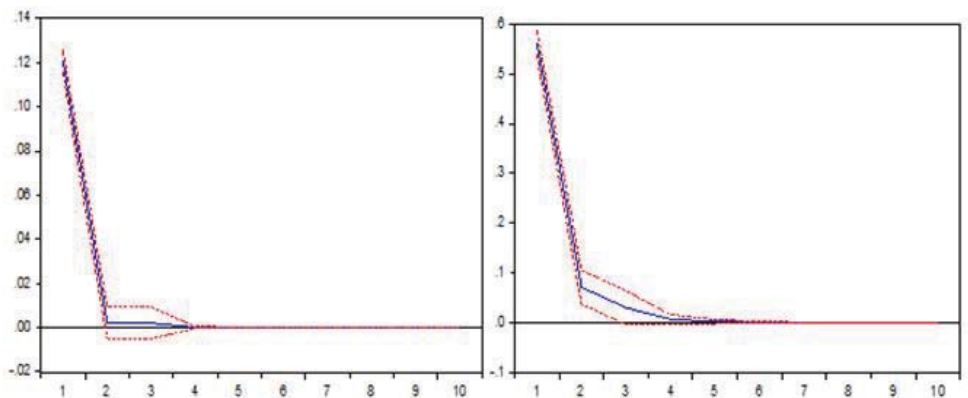

\section{Conclusion}

This study examined the extent to which a long-run relationship exists between the price and NAV of South African domestic ETFs. For all the funds, it was found that a long-run equilibrium relationship between price and NAV exists; however, this only conformed with the law of one price for three of the funds. That is, for these funds, the deviations between price and NAV can be viewed as temporary aberrations and in the long-run the two series will move together. But, for the Satrix FINI, the equilibrium relationship intimates that the funds trade at a significant discount to the NAV and this is likely to persist. An analysis of a shock to the cointegrating relationship revealed that equilibrium is restored relatively quickly for the funds (approximately one to two days), with both the fund NAV and price adjusting to restore equilibrium. The finding that the price adjusts to restore equilibrium confirms that arbitrageurs are present in the market to trade on mispricing on the funds. However, the finding that the NAV also corrects for disequilibrium is surprising and warrants further investigation. It may reflect that price discovery in these funds does not originate with the NAV, as would be expected, but may occur in both the price of the ETF and the constituent components of the fund.

Given the size and appeal of the ETF market in South Africa, it is reassuring for investors to know that these securities are close to being efficiently priced, although the results of this study did raise some concerns regarding the Satrix FINI. However, given the findings internationally, it is definitely necessary to extend this research to consider the price efficiency of international ETFs that are listed on the South African market, especially as they represent an easy means for investors to diversify their portfolios outside of the South African market. Moreover, given ETFs are primarily proffered as an outlet for passive investors rather than index-funds or index-futures, it is worth examining whether ETFs provide a better tracking measure than either of the more traditional products for achieving passive investment management.

\section{References}

Ackert L., \& Tian Y. (2000). Arbitrage and valuation in the market for Standard and Poor's Depositary Receipts. Financial Management, 29(3): 71-87.

Asteriou, D., \& Hall, S. (2011). Applied Econometrics. (2nd ed.). Hampshire: Palgrave MacMillan.

Charteris, A. (2013). The price efficiency of South African Exchange Traded Funds. Investment Analysts Journal, 78:17-26

Cherry, J. (2004).The limits of arbitrage: Evidence from exchange traded funds. Honours Dissertation, Department of Finance, University of California-Berkeley, California.

De Fusco, R., Ivanov, S., \& Karels, G. (2011). The exchange traded funds' pricing deviation: Analysis and forecasts. Journal of Economics and Finance, 35: 181-197.

Deville, L. (2008). Exchange traded funds: History, trading and research. In: Zopounidis, C., Doumpos, M., \& Pardalos, P. (Ed.). Handbook of Financial Engineering. New York: Springer, 1-37.

Delcoure, N. \& Zhong, M. (2007). On the premiums of i-Shares. Journal of Empirical Finance, 14(2): 168-195.

Elton, E., Comer, G., \& Li, K. (2002). Spiders: Where are the bugs? Journal of Business, 75(3): 453-472.

Engle, R., \& Sarkar, D. (2006). Premiums-discounts and exchange traded funds. Journal of Derivatives, Summer: 27-45.

Fujiwara, K. (2006(. Does the Japanese closed-end puzzle exist? An empirical study of the efficiency of the financial market in Japan? International Journal of Business, 11(1): 35-47.

Gallagher, D., \& Segara, R. (2005). The performance and trading characteristics of exchange-traded funds. Working Paper, University of New South Wales, New South Wales.

Gastineau, G. (2002). The Exchange-Traded Funds Manual. New Jersey: John Wiley \& Sons. 
Gastineau, G. (2004). The benchmark index ETF performance problem. Journal of Portfolio Management, 30(2): 96-103.

Hasbrouck, J. (1995). One security, many markets: Determining the contributions to price discovery. Journal of Finance, 50(4): 11751199.

Jares, T., \& Lavin, A. (2004). Japan and Hong-Kong exchange-traded funds: Discounts, returns and trading strategies. Journal of Financial Services Research, 25(1): 57-69.

Kayali, M. (2007). Pricing efficiency of exchange traded funds in Turkey: Early evidence from the Dow Jones Istanbul 20. International Research Journal of Finance and Economics, 10 (July): 14-23.

Kostovetsky, L. (2003). Index mutual funds and exchange-traded funds. Journal of Portfolio Management, 29(4): 80-92.

Lin, C., Chan, S., \& Hsu, H. (2005). Pricing efficiency of exchange traded funds in Taiwan. Journal of Asset Management, 7(1): 60-68.

MacKinnon, J., Haug, A., \& Michelis, L. (1999). Numerical distribution functions of likelihood ratio tests for cointegration. Journal of Applied Econometrics, 14(5): 563-577.

Pesaran, M., \& Shin, Y. (1996). Cointegration and speed of convergence to equilibrium. Journal of Econometrics, 71: 117-143.

Toda, H. \& Yamamoto, T. (1995). Statistical inferences in vector autoregressions with possibly integrated processes. Journal of Econometrics, 66: 225-250.

Tse, Y., \& Martinez, V. (2007). Price discovery and informational efficiency of international iShares funds. Global Finance Journal, 18: 115. 